\title{
Anti-fatigue effects of polysaccharides extracted from Rhodiolae Radix
}

\author{
Fenglin $\mathrm{Li}^{1,2}$, ${ }^{*}$ Furen $\mathrm{Xiao}^{1}$, Junsheng $\mathrm{Qi}^{3}$ \\ ${ }^{1}$ College of Materials Science and Engineering, Yanshan University, Qinghuangdao, 066004, China \\ ${ }^{2}$ Jilin Agricultural Science and Technology College, Jilin, 132101, China \\ ${ }^{3}$ Institute of Special Animal and Plant Sciences (ISAPS) of Chinese Academy of Agricultural Sciences, Jilin, 132109, China
}

\begin{abstract}
The purpose of the present study was to determine the effects of polysaccharide from Rhodiolae Radix (PRR) on physical fatigue using a forced swimming test in male mice. 96 mice were divided randomly into four groups based on body weight $(n=24)$. One of the groups was the control group; the others were PRR supplemented groups $(25,50$ and $100 \mathrm{mg} / \mathrm{kg}$ body weight). Forced swimming test of mice were carried out after 28 days of PRR administration, and the blood lactic acid (BLA), blood urea nitrogen (BUN), liver glycogen and muscle glycogen contents were determined. The data suggest that PRR can extend the exhaustive swimming time of the mice, as well as increase the tissue glycogen contents, and decrease the BLA and BUN contents. These results indicated that PRR had significant antifatigue effects.
\end{abstract}

Key Words: Polysaccharide from Rhodiolae Radix, physical fatigue, forced swimming test, mice.

\section{INTRODUCTION}

Rhodiola sachalinensis A. BOR belongs to the family Crassulaceae, and the root of the plant (Gao-shanhong-jing-tian in Chinese), Rhodiolae Radix, have been widely used as a hemostatic, antibechic, tonic, and endermic liniment for burns and contusions in traditional Chinese medicine (Khanum et al., 2006; Ming et al., 2005). Many studies have reported that Rhodiolae Radix has many important biological activities, including adaptogenic, antihypoxia, antioxidant, anti-inflammatory, antivirus, antidiabetic, anticancer, immune enhancing and sexually stimulating properties (Bawa and Khanum, 2009; Kim et al., 2007; Li et al., 2011). Rhodiolae Radix is reported to contain a range of biologically active substance including phenylpropanoids (rosavins, rosin); phenylethanol derivatives (salidroside, tyrosol), organic acids, flavonoids, polysaccharides, tannins and phenolic glycosides (Gupta et al., 2008). To date, its biological activities are mainly attributed to salidroside and the phenylpropanoids. However, recent studies have suggested that the polysaccha-

\footnotetext{
*Corresponding Author:

Furen Xiao, Professor

College of Materials Science and Engineering

Yanshan University

Qinghuangdao, 066004, China

E-mail:swgclifenglin@sina.com

Contact No.: +86013089189488
}

ride from Rhodiolae Radix (PRR) also exhibit significant biological activities, including antivirus, antidiabetic, immune enhancing and promote the recovery of hematopoietic function in myelosuppressed (Li et al., 2011). To our knowledge, there have been limited studies investigating the effects of PRR on physical fatigue. Therefore, the purpose of the present study was to determine the effects of PRR on physical fatigue using a forced swimming test in male mice.

\section{MATERIALS AND METHODS}

\section{Plant materials and reagents}

Rhodiolae Radix was purchased from a local drug market and the material was identified by Mr. Wang Guang Yao, a botanist of Jilin Agriculture Science and Technology College. A voucher specimen (No. 0429161) has been deposited in herbarium of Jilin Agriculture Science and Technology College. The dried Rhodiolae Radix was ground in a high speed disintegrator (Model HDV, Dongying Hongjiu Traditional Medicine Machine Company, Shandong, China) to obtain a fine powder (Particle diameter size: $1-2 \mathrm{~mm}$ ). The powder was stored at $4^{\circ} \mathrm{C}$ until use. Assay kits for determination of blood lactic acid (BLA), blood urea nitrogen (BUN), tissue glycogen were purchased from Nanjing Jiancheng Biotech- 
nology Institute (Nanjing, China). All other chemicals used were analytical grade. Water was purified with a Milli-Q purification system and was used to prepare all solutions.

\section{Animals}

All experiments were performed in accordance with the Guide for the Care and Use of Laboratory Animals of the Chinese National Institutes of Health. Male Kun-Ming strain mice weighing $20 \pm 2 \mathrm{~g}$ were obtained from Jiuzhan Biochemical Factory (Jilin, China). The animals were housed in a room maintained at $23 \pm 2{ }^{\circ} \mathrm{C}$ with relative air humidity of $45 \%$ to $55 \%$ on a 13-hour light/11-hour dark cycle. Mice were provided a standard laboratory chow and water ad libitum (Sharma et al., 2012). The study protocol was approved by the animal research ethics committee at Jilin Agricultural Science and Technology (Jilin, China).

\section{Preparation of polysaccharide from Rhodiolae Radix}

The powder of Rhodiolae Radix was extracted in a Soxhlet apparatus with a mixture of chloroformmethanol $\left(2: 1,75^{\circ} \mathrm{C}\right)$, and pretreated with $80 \%$ ether twice to remove some coloured materials, oligosaccharides, and some small molecule materials. The organic solvent was volatilized and pretreated dry powder was obtained. Then the pretreated powder was extracted with distilled water in a microwave extraction apparatus (WD800ASL Galanz Co., Shunde, China) at a selected extraction conditions (solid-liquid ratio of $1: 45 \mathrm{~g} / \mathrm{mL}$, irradiation power of $480 \mathrm{~W}$, and irradiation time of $8 \mathrm{~min}$ ). After the extraction with microwave treatment, the extracts was centrifuged (2000g, $20 \mathrm{~min})$, then the supernatant was separated from insoluble residue with nylon cloth (pore diameter: $38 \mathrm{um}$ ). The extracts were then defatted by the method of Sevag, precipitated by the addition of ethanol to a final concentration of $80 \%$ $(\mathrm{v} / \mathrm{v})$, and the precipitates were collected by centrifugation $(2000 \mathrm{~g}, 20 \mathrm{~min})$. It was then solubilized in deionized water and lyophilized to get polysaccharides from Rhodiolae Radix (PRR).

\section{Animals grouping and treatment}

The mice were adapted to diet and environment for one week before the experiment began. 96 mice were divided randomly into four groups based on body weight $(n=24)$, such as control $(C)$ group, lowdose PRR supplemented (L) group, middle-dose
PRR supplemented (M) group and high-dose PRR supplemented $(\mathrm{H})$ group. The mice in the control group were orally administered physiological saline of $50 \mathrm{~mL} / \mathrm{kg}$ bodyweight per day for 28 days, while the PRR supplemented group received the same volume of PRR of 25,50 and $100 \mathrm{mg} / \mathrm{kg}$ bodyweight. The doses used in this study were confirmed to be suitable and effective in tested mice according to preliminary experiments.

\section{Forced swimming test}

The forced swimming test was employed in this study to evaluate the effects of PRR on physical fatigue. The apparatus used in this test was an acrylic plastic pool $(50 \mathrm{~cm} \times 50 \mathrm{~cm} \times 40 \mathrm{~cm})$ filled with water maintained at $25 \pm 2^{\circ} \mathrm{C}$. The water in the acrylic plastic pool was $30 \mathrm{~cm}$ deep. Eight mice were taken out from each group to make forced swimming test after being administrated with different dose of PRR for 28 days. Each mouse's tail was loaded with galvanized wire, which was $5 \%$ of its body weight (Yao and Li, 2010). Mice were regarded as being exhausted when they were underwater for $10 \mathrm{~s}$ (Miao et al., 2010). The time of each group of mice was averaged and the data of the different groups was analyzed.

\section{Analysis of blood lactic acid contents}

Eight mice were taken out from each group for BLA analyses after being administrated with different dose of PRR for 28 days. Mice were forced to swim $10 \mathrm{~min}$ without a load. $20 \mu \mathrm{L}$ of blood from the inner canthus of the eye was collected using capillary tubes after the last administration of PRR. Another $20 \mu \mathrm{L}$ of blood samples was collected immediately after mice have been swimming. Then BLA was tested following the recommended procedures provided by the kits.

\section{Analysis of blood urea nitrogen and tissue glyco- gen contents}

The other eight mice were taken out from each group for BUN and tissue glycogen analyses after being administrated with different dose of PRR for 28 days. Mice were forced to swim $90 \mathrm{~min}$ without a load. Rested for $60 \mathrm{~min}$, the mice were killed to collect blood samples, liver and gastrocnemius muscle. Then BUN, liver glycogen and muscle glycogen was tested following the recommended procedures provided by the kits. 


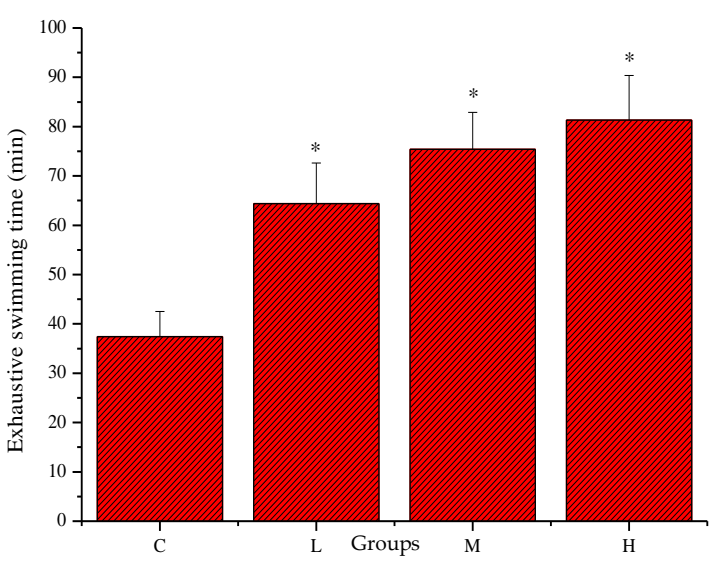

Figure 1: Effect of PRR on exhaustive swimming time of mice. ${ }^{*} \mathrm{P}<0.05$ when compared to the $\mathrm{C}$ (control) group.

\section{Statistical analysis}

All data in table are expressed as mean \pm SD and differences between groups were assessed by analysis of variance (ANOVA) and Student's t-test. Differences were considered to be statistically significant if $\mathrm{P}<0.05$. All statistical analyses were carried out using SPSS for Windows, Version 11.5 (SPSS, Chicago, IL).

\section{RESULTS AND DISCUSSION}

Effect of PRR on exhaustive swimming time of mice The forced swimming test has been used to evaluate the anti-fatigue effects of medicine, since this apparatus works well for evaluating the endurance capacity of mice and gives a high reproducibility (Zhang and Wang, 2012). To standardize the workload and reduce the swimming time, weights at specific body weight percentages were added to the chest or tail of the animal (Hao and Zhaobao, 2010). As shown in figure 1, the exhaustive swimming time of $\mathrm{L}, \mathrm{M}$ and $\mathrm{H}$ groups were significantly longer than that of $C$ group $(P<0.05)$. The results indicated that PRR had anti-fatigue effects and could elevate the exercise tolerance.

\section{Effect of PRR on blood lactic acid contents of mice}

Lactic acid was considered a metabolic end product of glycolysis and a potential candidate for inducing fatigue (Yao and Li, 2010). Some studies indicated that when lactic acid builds up in myocytes, intracellular $\mathrm{pH}$ drops, contributing to the onset of fatigue (Murase et al., 2006). As shown in figure 2, before swimming, BLA contents were not significantly different between groups ( $P>0.05)$, but after



Figure 2: Effect of PRR on blood lactic acid contents of mice. ${ }^{*} \mathrm{P}<0.05$ when compared to the $\mathrm{C}$ (control) group.

forced swimming, the BLA contents of $\mathrm{L}, \mathrm{M}$ and $\mathrm{H}$ groups were significantly lower than that of $\mathrm{C}$ group $(\mathrm{P}<0.05)$. The results indicated that $P R R$ could effectively delay the increase of lactate in the blood and postpone the appearance of physical fatigue.

\section{Effect of PRR on Blood Urea Nitrogen Contents of Mice}

Blood urea nitrogen is a sensitive index to evaluate the bearing capability when human bodies suffer from a physical load (Zhang et al., 2006). Growing evidence indicates that urea nitrogen in the blood rises significantly for a long-run athlete after exercise (Wang et al., 2006; Zhang et al., 2009). There is a positive correlation between the urea nitrogen in vivo and the exercise tolerance. As shown in figure 3 , after forced swimming, the BUN contents of $\mathrm{H}$ group were significantly lower than that of $C$ group $(\mathrm{P}<0.05)$. Although the BUN contents of $\mathrm{M}$ and $\mathrm{L}$ groups were also decreased, no significant difference was observed $(P>0.05)$. The results indicated that high doses of PRR might reduce catabolic decomposition of protein for energy, which is indicative of enhanced endurance.

\section{Effect of PRR on Tissue Glycogen Contents of Mice} Energy for exercise is derived initially from the breakdown of glycogen, after strenuous exercise muscle glycogen will be exhausted, and later, energy will form circulating glucose released by the liver. Thus, the glycogen contents are sensitive parameters related to fatigue (You et al., 2012; Zhang et al., 2010). As shown in figure 4, after forced swimming, the liver glycogen and muscle glycogen contents of $\mathrm{L}, \mathrm{M}$ and $\mathrm{H}$ groups were significantly higher than that of $\mathrm{C}$ 


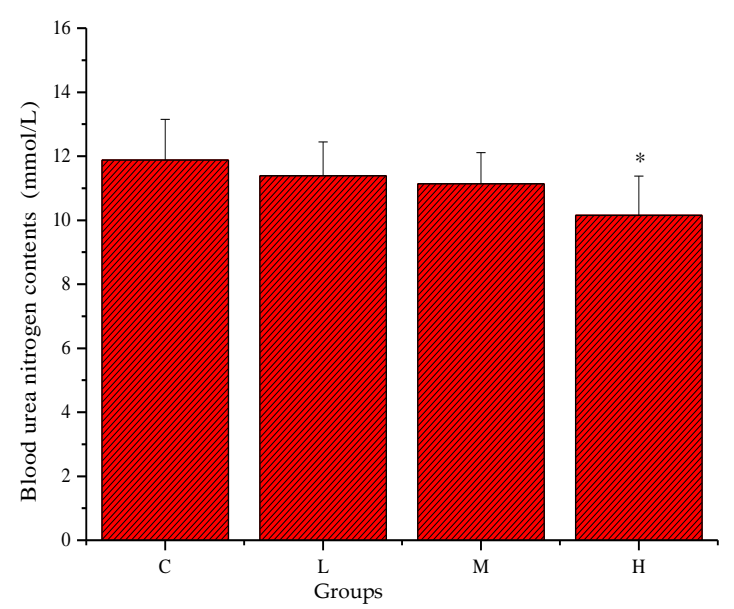

Figure 3: Effect of PRR on blood urea nitrogen contents of mice. ${ }^{*} \mathrm{P}<0.05$ when compared to the $\mathrm{C}$ (control) group.

group $(\mathrm{P}<0.05)$. The results indicated that $P R R$ could promote sparing of glycogen. The glycogen sparing effect of PRR can provide an important survival advantage in situations requiring extended periods of prolonged endurance exercise. It is possible that PRR might have promoted glycogenolysis restraint or gluconeogenesis.

\section{CONCLUSION}

In conclusion, the data suggest that PRR can extend the exhaustive swimming time of the mice, as well as increase the tissue glycogen contents, and decrease the blood lactic acid and blood urea nitrogen contents. From the present findings, we can conclude that PRR had significant anti-fatigue effects. However, further studies to clarify the detailed mechanisms involved in the anti-fatigue effects of PRR are necessary.

\section{ACKNOWLEDGEMENT}

This work was supported by the Natural Sciences Foundation of Jilin Province of China (Grant No. 20120918) and Reserve projects Foundation of Jilin Agricultural Science and Technology College.

\section{REFERENCES}

Bawa, A. and Khanum, F. (2009) Anti-inflammatory activity of Rhodiola rosea-"a second-generation adaptogen". Phytother Res, vol. 23, pp. 1099-1102. [DOI]

Gupta, V., Saggu, S., Tulsawani, R., Sawhney, R. and Kumar, R. (2008) A dose dependent adaptogenic and safety evaluation of Rhodiola imbricata Edgew, a high altitude rhizome. Food Chem Toxicol, vol. 46, pp. $1645-1652$. [DOI]

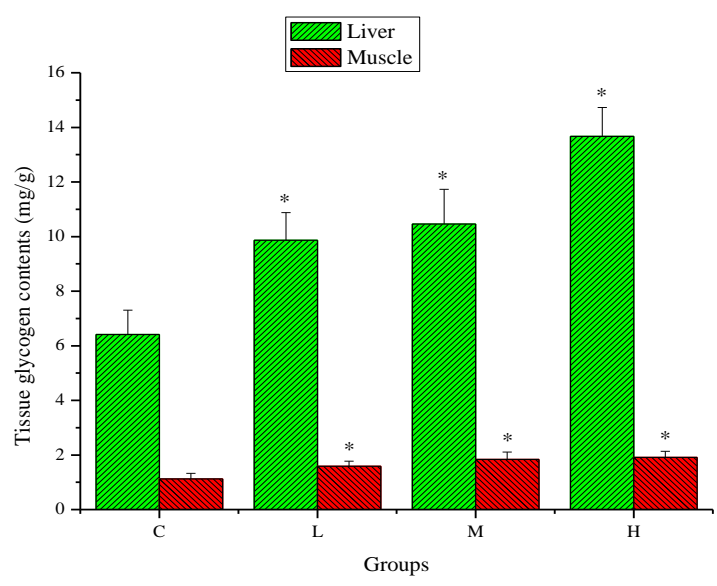

Figure 4: Effect of PRR on liver glycogen and muscle glycogen of mice. ${ }^{*} \mathrm{P}<0.05$ when compared to the $\mathrm{C}$ (control) group.

Hao, S. and Zhaobao, W. (2010) Effects on exercise endurance capacity and antioxidant properties of astragalus membranaceus polysaccharides (APS). J Med Plants Res, vol. 4, pp. 982-986. [DOI]

Khanum, F., Bawa, A. S. and Singh, B. (2006) Rhodiola rosea: a versatile adaptogen. Compr Rev Food Sci F, vol. 4, pp. 55-62. [DOI]

Kim, C., Kwon, M., Qadir, S. A., Hwang, B., Nam, J. and Lee, H. (2007) Toxicity reduction and improvement of anticancer activities from Rhodiola sachalinensis A. Bor by ultra high pressure extracts process. Korean J Med Crop Sci, vol. 15, pp. 411-416.

Li, F., Tang, H., Xiao, F., Gong, J., Peng, Y. and Meng, X. (2011) Protective effect of salidroside from Rhodiolae radix on diabetes-induced oxidative stress in mice. Molecules, vol. 16, pp. 9912-9924. [DOI]

Miao, F., Yu, W., Wang, Y., Wang, M., Liu, X. and Li, F. (2010) Effects of corn peptides on exercise tolerance, free radical metabolism in liver and serum glutamic-pyruvic transaminase activity of mice. Afr J Pharm Pharmacol, vol. 4, pp. 178-183.

Ming, D. S., Hillhouse, B. J., Guns, E. S., Eberding, A., Xie, S., Vimalanathan, S. and Towers, G. (2005 Bioactive compounds from Rhodiola rosea (Crassulaceae). Phytother Res, vol. 19, pp. 740-743. [DOI]

Murase, T., Haramizu, S., Shimotoyodome, A., Tokimitsu, I. and Hase, T. (2006) Green tea extract improves running endurance in mice by stimulating lipid utilization during exercise. Am J Physiol Regul Integr Comp Physiol, vol. 290, pp. R1550-R1556. [DOI]

Sharma A, Sangameswaran B, Jain V, Saluj M S. (2012) Hepatoprotective activity of Adina cordifolia against ethanol induce hepatotoxicity in rats. Int Curr Pharmaceut J, vol. 1, pp. 279-284. [DOI]

Wang, J. J., Shieh, M. J., Kuo, S. L., Lee, C. L. and Pan, T. M. (2006) Effect of red mold rice on antifatigue and exercise-related changes in lipid peroxidation in endurance exercise. Appl Microbiol Biotechnol, vol. 70, pp. 247-253. [DOI]

Yao, L. and Li, F. (2010) Lycium barbarum polysaccharides ameliorates physical fatigue. Afr J Agric Res, vol. 5, pp. 2153-2157. [DOI]

You, L., Ren, J., Yang, B., Regenstein, J. and Zhao, M. (2012) Antifatigue activities of loach protein hydrolysates with different antioxidant activities. J Agric Food Chem, vol. 60, pp. 12324-12331. [DOI]

Zhang, L., Shan, Y., Tang, K. and Putheti, R. (2009) Ultrasound-assisted extraction flavonoids from Lotus (Nelumbo nuficera Gaertn) leaf and evaluation of its anti-fatigue activity. Int J Phys Sci, vol. 4, pp. 418-422.

Zhang, X. L., Ren, F., Huang, W., Ding, R. T., Zhou, Q. S. and Liu, X. W. (2010) Anti-fatigue activity of extracts of stem bark from Acanthopanax senticosus. Molecules, vol. 16, pp. 28-37. [DOI]

Zhang, Y. and Wang, B. (2012) Effects of polysaccharides from Cordyceps sinensis mycelium on physical fatigue in mice. Bangladesh J Pharmacol, vol. 7, pp. 217-221. [DOI]

Zhang, Y., Yao, X. and Bao, B. (2006) Anti-fatigue activity of a triterpenoid-rich extract from Chinese bamboo shavings (Caulis bamfusae in taeniam). Phytother Res, vol. 20, pp. 872-876. [DOI] 